\title{
вмJ Global Health The impact of country reimbursement programmes on living kidney donations
}

\author{
Abu Bakkar Siddique (D) ,' Vandana Apte, ${ }^{2}$ Sigrid Fry-Revere, ${ }^{3}$ Yanhong Jin, ${ }^{2}$ \\ Naoru Koizumi (iD ${ }^{1}$
}

To cite: Siddique AB, Apte $V$, Fry-Revere $\mathrm{S}$, et al. The impact of country reimbursement programmes on living kidney donations. BMJ Global Health 2020;5:e002596. doi:10.1136/ bmjgh-2020-002596

Handling editor Seye Abimbola

- Additional material is published online only. To view please visit the journal online (http://dx.doi.org/10.1136/ bmjgh-2020-002596).

Received 6 April 2020 Revised 23 June 2020 Accepted 24 June 2020

Check for updates

(C) Author(s) (or their employer(s)) 2020. Re-use permitted under CC BY-NC. No commercial re-use. See rights and permissions. Published by BMJ.

${ }^{1}$ Schar School of Policy and Government, George Mason University-Arlington Campus, Arlington, Virginia, USA

${ }^{2}$ Department of Agricultural, Food and Resource Economics, Rutgers University, New Brunswick, New Jersey, USA ${ }^{3}$ Independent Bioethics Scholar, Washington, District of Columbia, USA

Correspondence to Mr. Abu Bakkar Siddique; anirbanju36@gmail.com

\section{ABSTRACT}

Introduction Living-donor kidney transplantation is the gold standard treatment for patients with end-stage kidney disease. However, potential donors ubiquitously face financial as well as logistical barriers. To remove these disincentives from living kidney donations, the governments of 23 countries have implemented reimbursement programmes that shift the burdens of nonmedical costs from donors to the governments or private entities. However, scientific evidence for the effectiveness of these programmes is scarce. The present study investigates whether these reimbursement programmes designed to ease the financial and logistical barriers succeeded in increasing the number of living kidney donations at the country level. The study examined withincountry variations in the timing of such reimbursement programmes.

Method The study applied the difference-in-difference (two-way panel fixed-effect) technique on the Poisson distribution to estimate the effects of these reimbursement programmes on a 17 year long (2000-2016) dataset covering 109 countries where living donor kidney transplants were performed.

Results The results indicated that reimbursement programmes have a statistically significant positive effect. Overall, the model predicted that reimbursement programmes increased country-level donation numbers by a factor of 1.12-1.16.

Conclusion Reimbursement programmes may be an effective approach to alleviate the kidney shortage worldwide. Further analysis is warranted on the type of reimbursement programmes and the ethical dimension of each type of such programmes.

\section{INTRODUCTION}

Kidney transplantation is the definitive and gold standard treatment for patients with end-stage kidney disease. ${ }^{1}$ However, access to this treatment is severely hindered by the steadily worsening kidney shortage: while the demand for transplants is continuously rising with the growing prevalence of chronic kidney disease, the supply of kidneys is not increasing at a similar rate. ${ }^{2}$ In the USA, the median wait time for a kidney transplant is about 4 years, and close to 5000 patients die every year on the transplant waitlist. ${ }^{3}$ Worse,

\section{Key questions}

\section{What is already known?}

- There is mixed evidence on the impact of livingdonor reimbursement programmes on the donation rate.

- In the USA, prior literature found no significant impacts of such programmes on the donor rates at the state level.

- No prior literature has evaluated the impacts of such programmes at the country level.

What are the new findings?

- There is a significant variation in the living kidney donation rate worldwide.

- At the country level, the existence of a reimbursement programme has a clear positive association with the living kidney donation rate.

- Social and economic globalisations, as well as limited availability of deceased donor kidneys, are positively correlated with living kidney donation rate.

\section{What do the new findings imply?}

- Implementation of a living-donor reimbursement programme may be an effective policy to alleviate the kidney shortage. Programmes are more effective in relatively less developed economies.

- The type of the reimbursement programmes and their impacts need to be further researched.

this number does not include those patients who are removed from the waitlist due to disease progression and other related complications that make them too sick to receive a transplant. ${ }^{4}$ As such, patients with end-stage kidney disease, transplant centres, policymakers and other members of the transplant community have a vested interest in increasing kidney donation.

Access to living donor (LD) kidney transplants, which generally provide better outcomes, is hampered by various burdens on donors, including the potential loss of quality of life, possible post-donation complications (such as infections and abdominal problems), and risk of kidney failure or death. The estimated risk involves approximately 3.1 deaths per every 10000 kidney donors. ${ }^{56}$ Other risks 
include a potential lack of informed consent and a lack of clarity regarding recovery times and long-term effects, making it hard for donors to fully understand the extent of the risks that they are taking and what compensation would be necessary to balance those risks. ${ }^{7}$ Some of the financial costs, such as costs of recovery or complications, time away from workplace, travel and accommodations, can be eliminated through reimbursement programmes. To eliminate some of the disincentives for potential LDs, many countries have initiated some types of reimbursement programmes. Most of these programmes aim to compensate donors for some of the financial costs.

While these programmes have been implemented long enough, more than two decades in the USA, there has been limited literature examining the effectiveness of these policies. Overall, the literature suggests little to no effect of these policies on living kidney donation in the USA. ${ }^{8}$ For instance, the effects of the state-level tax credit and paid leave laws were studied and are shown to have no impact. ${ }^{8}{ }^{9}$ Compensation policies to cover medical, lodging and wage losses are also known to have no effect. ${ }^{9}$ At the global scale, so far, there have been no retrospective studies examining the effectiveness of such policies. Thus, the present study constructed comprehensive panel data to quantitatively evaluate the effectiveness of the LD compensation policies worldwide.

We structured our paper in the following manner. The next section describes the data and the method. Results section presents the results. Discussion section further discusses the results in light of prior research in this area. Limitations section and Conclusion section provide the limitations and the conclusion of the present study, respectively.

\section{METHODS \\ Data}

The country-level panel data from 109 countries was constructed for the period between 2000 and 2016. The information on LD compensation policies was gathered from various sources. Sickand et al. provided the information of reimbursement programmes in 40 countries: whether they have any government and nongovernment reimbursement programmes and, if they do, the programme's eligibility criteria, duration, types of expenses reimbursed and reimbursement mechanism. ${ }^{10}$ These programmes mainly facilitated reimbursement to LDs for non-medical expenses such as travel, accommodation, meal, lost income, childcare, etc. The Google search of government, nephrology and transplantation foundations' websites, as well as policy papers, identified an additional 45 countries without reimbursement programmes. For the other 24 countries, no information on the LD compensation policy was available. These countries were considered to have no compensation policy because the lack of online information would most likely hinder public awareness about the policy even if it existed, which would de facto mean the non-existence of such a programme. The final dataset contained 23 countries that have implemented some type of compensation programme for the living kidney donors.

The outcome (dependent) variable, that is, the total number of living kidney donors in the country, was extracted from the Global Observatory on Donation and Transplantation and the International Registry on Organ Donation and Transplantation databases. In addition to the presense of a reimbursement programme in the country, we collected data on various other factors potentially affecting the number of LDs. Those included the country-level demographic, financial, health and political-related factors. For demographic and economic variables, we explored the population size, Gross Domestic Product (GDP) per capita, and the GDP growth rate. A larger population increases the pool of potential donors, and thus possibly a larger number of LDs. A higher GDP is likely to reduce various challenges associated with living donation. For health-related variables, we explored the ratio of public and private health expenditure to GDP and the average out-of-pocket health expenditure. Higher health expenditure is, in general, an indication of a relatively advanced healthcare system or infrastructure. The advanced system may reduce the fear associated with living donation, or it could mean that the country has a more advanced deceased donor transplant system which may, in turn, reduce the overall incentive or need for LD transplants. We also controlled for the number of deceased donors, which may encourage living donation if deceased kidney donation promotes the overall donation culture. Or the presense of such an alternative may reduce the incentive for living donation. Other control variables included were the county's political globalisation, social globalisation and financial globalisation indices. Political globalisation is associated with the government's ability to impose tax and change policies. ${ }^{11}$ Financial globalisation reflects Foreign Direct Investment(FDI), portfolio investment, international debt, international reserves and international income payment. ${ }^{11}$ Social globalisation captures different factors of information, culture, internet usage, migration, transfers, tourism and others. ${ }^{11}$ The globalisation indices were taken from the Swiss economic institute Konjunkturforschungsstelle index. These composite indices are standard controls included in the literature using country-level panel regression analyses to compensate missing values/variables in the data of some countries or years. ${ }^{12} 13$ Online supplementary appendix II presents more information about these globalisation indices.

\section{Patient and public involvement}

There were no patient or public involvement. This restospective study was performed only using publicly available/downloadable country-level data.

\section{Statistical analysis}

We applied time averages to interpolate the values for missing years where data exhibited a clear time trend. 
This increased the number of observations from 1453 to 1519 in the balanced panel. No data extrapolation was performed. For the regression, a non-linear model was applied to accommodate the outcome variable, that is, the number of living kidney donors, which takes on count/discrete values. The model incorporated country and year fixed effects (FE) to control for timeinvariant country-level observable and non-observable confounders and country-wide secular trends in donations. We specifically used a Poisson model as opposed to a negative binomial model since the conditional fixedeffect negative binomial model for count panel data does not control for individual FE unless a very specific set of assumptions are met. ${ }^{1415}$ To estimate the programme effect on the outcome variable, we took the difference and difference $(\mathrm{DiD})$ approach with a dummy variable reflecting the presence of a compensation programme. The approach exploits the fact that different countries have introduced compensation programmes at different points in time, thereby capturing the programme effects both within and across the countries over the study period. Our main interest lies in within-country variation since we aim to make an inference about the causality of a reimbursement programme instead of the simple association between the programme existence and the number of LDs.

The basic set-up of the DiD regression model involves: countries with a reimbursement programme $(i=1)$ and those countries without $(i=0)$, and two time periods representing preprogramme $(t=0)$ and postprogramme $(t=1)$ implementation. In the Poisson set-up, it is specified as follows:

$$
\begin{aligned}
\log \left(\mathrm{E}\left(\mathrm{Y}_{\mathrm{it}} \mid \mathrm{X}_{\mathrm{it}}\right)=\right. & \beta_{0}+\beta_{1} \operatorname{ReimProg}_{\mathrm{i}}+\beta_{2} \text { Post }_{\mathrm{t}}+ \\
& \beta_{3} \text { ReimProg }_{\mathrm{i}} * \text { Post }_{\mathrm{t}}+\beta_{4} \mathrm{X}_{\mathrm{it}}+\varepsilon_{\mathrm{it}} \ldots
\end{aligned}
$$

where $Y_{i t}$ is the number of LDs in country $i$ at time $t$, ReimProg $_{i}$ is an indicator variable for the countries with a reimbursement programme, Post $_{t}$ represents the postprogramme time period and ReimProg $i *$ Post $_{t}$ is the interaction term between the postprogramme period and the countries with a reimbursement programme. $\mathrm{X}_{i t}$ is the countrylevel covariates and $\varepsilon_{i t}$ is the error term. Our primary interest is $\beta_{3}$, which is the estimator for the average effect of the country-level reimbursement programmes.

\section{RESULTS \\ Descriptive analysis}

There were 23 countries that implemented an LD reimbursement programme during the study period. Of those, 12 countries had a programme throughout the 17 years, while 10 countries implemented a programme after 2000 (figure 1). None of these countries ceased their reimbursement programmes during the period. The figure presents the (cumulative) evolution of the reimbursement programmes worldwide. The reimbursement programmes covered five broad categories of non-medical expenses such as travel, accommodation, meal, income loss and childcare. There was limited variation in the reimbursement components seen across the countries, that is, if a country had a reimbursement programme, it tended to have all of these components with a few exceptions. While the full picture of the programme was not available for all countries, we noted that at least Denmark, France, Netherlands, Israel,

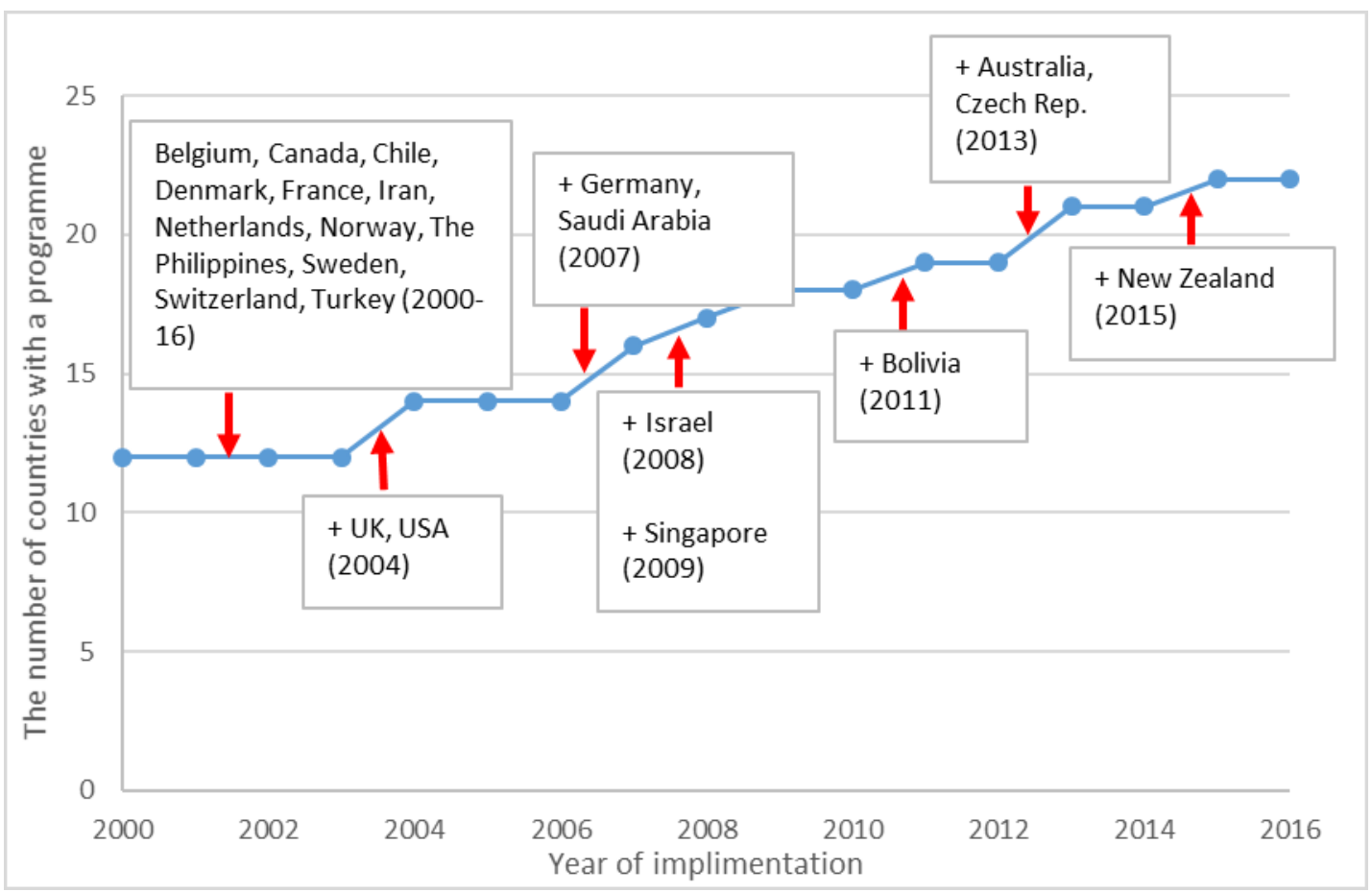

Figure 1 Evolution of country reimbursement programme: (2000-2016). 
Table 1 Descriptive statistics of key variables used in the analysis

\begin{tabular}{|c|c|c|c|c|c|}
\hline Variable & Mean or $\%$ & No of observations & SD & Min. & Max. \\
\hline No of living donors per million population*, mean & 7.56 & 1453 & 8.46 & 0 & 64 \\
\hline No of deceased donors per million population*, mean & 8.21 & 1451 & 8.99 & 0 & 44 \\
\hline Presence of reimbursement programmes, \% & $10 \%$ & 2975 & $29 \%$ & $10 \%$ & $29 \%$ \\
\hline Population growth rate, mean & 1.52 & 2970 & 1.55 & -3 & 16 \\
\hline Population size (per million), mean & 37.58 & 2903 & 137.27 & 0 & 1394 \\
\hline GDP growth rate & 4.04 & 2940 & 6.06 & -62 & 179 \\
\hline GDP per capita (thousand) & 12.93 & 2921 & 18.26 & 0.19 & 111.97 \\
\hline Health expenditure/GDP, mean & 6.22 & 3712 & 2.77 & 1 & 27 \\
\hline Health expenditure per capita, mean & 813.14 & 3724 & 1482.20 & 3 & 10005 \\
\hline Share (\%) of out of pocket health expenditure, mean & 35.18 & 3706 & 19.00 & 0 & 97 \\
\hline Social globalisation, mean & 56.64 & 2846 & 18.95 & 11 & 91 \\
\hline Financial globalisation, mean & 61.47 & 2778 & 19.34 & 15 & 100 \\
\hline Political globalisation, mean & 63.43 & 2846 & 22.00 & 6 & 100 \\
\hline Poverty head count ratio at US $\$ 3.2$ a day, mean & 29.51 & 1859 & 29.90 & 0 & 99 \\
\hline
\end{tabular}

${ }^{*}$ The numerator (the number of donors) reflects the interpolated values.

Philippines, Saudi Arabia, Norway, Singapore, Sweden and Switzerland had all of the five components. In online supplementary appendix I, we provided the list of the countries included in the analysis and the known status of the programme implementation.

Table 1 presents the summary statistics of the variables used in the analysis. The mean number of LDs was 7.56 per million population ( $\mathrm{pmp}$ ). There was a large variation in the donation rate worldwide. The donation rate for 2015 , for instance, varied from less than 1 to more than 40 per million (figure 2). In the figure, the countries coloured in yellow to green represent those countries with a relatively high donation rate, while the countries coloured in orange to red correspond to those with a relatively low donation rate. The countries with a relatively high level of donation included all (low-, middle- and high-) economy levels. Similarly, the countries with a relatively low level of donation included high-income and middleincome countries (Greece, Germany, Austria, France,

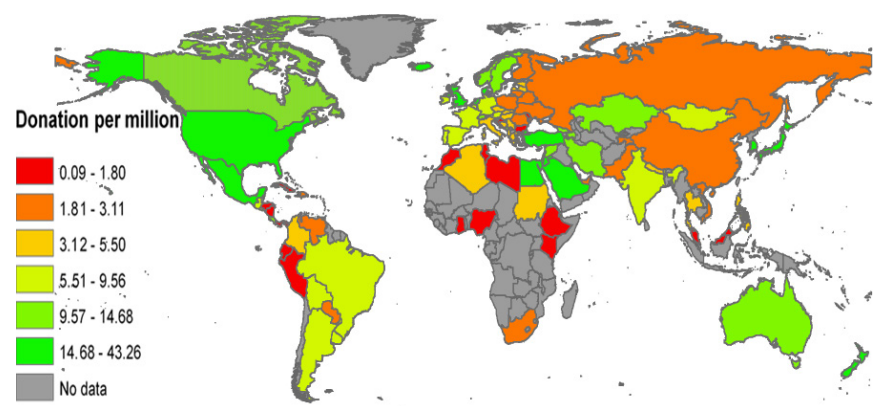

Figure 2 Donations per million by country in 2015. Note: authors' recreation of the map based on the data from Global Observatory on Donation and Transplantation and International Registry on Organ Donation and Transplantation. etc). In absolute numbers, only India and the USA had more than 5000 donors annually.

\section{Regression results}

Table 2 presents the regression results of the five models, each with a different set of independent variables. The overall goodness of fit was acceptable (wald_chi2 $=14209$, $\mathrm{p}<0.001)$, and there was no multicollinearity observed in the model $(\mathrm{VIF}=2.19)$. The reported coefficients are the log of expected counts in all models. Model 1 results show the DiD estimates with only one control, that is, the number of deceased donors, and the country and year FE. The coefficient of the reimbursement programme was positive and statistically significant $(p<0.01)$, indicating that the expected log count is approximately 0.05 units higher for the countries with a reimbursement programme than the countries with no reimbursement programme. In the incidence rate ratio (IRR) term, this indicates that, ceteris paribus, the number of LDs would be expected to increase by a factor of $1.05\left(=\mathrm{e}^{0.054}\right)$ or $5 \%$ in the presence of a reimbursement programme. The coefficient became larger $\left(\right.$ model 2: $I R R=e^{0.149}=1.16$; model 3: $\mathrm{IRR}=\mathrm{e}^{0.114}=1.12$; model $\left.4: \mathrm{IRR}=\mathrm{e}^{0.138}=1.15\right)$ with added controls (the ratio of health expenditure to GDP and out of pocket health expenditure in model 2, GDP per capita, GDP growth, population size and population growth rate in model 3, and the levels of financial, political and social globalisation in model 4), and remained consistently positive and statistically significant $(p<0.01)$ across the five models. Most of the control variables were consistently statistically significant. The number of deceased donors (measured in thousand) was negatively associated with the number of LDs. While the health expenditure ratio to GDP was negatively associated with LDs, the out of pocket health expenditure was positively 
associated. Similarly, financial and social globalisation levels and other economic variables (GDP and GDP per capita growth) were positively associated with living donation relatively consistently, but political globalisation was negatively associated $(\mathrm{p}<0.01)$. Population size was negatively correlated with donations $(\mathrm{p}<0.01)$ but its growth rate did not affect the donation level $(p>0.05)$ in any model. Model 5 excludes Iran and India from the data over a concern of unique patterns of living donations which may drive our findings. In Iran, the higher number of living donations is presumably driven by monetary compensation which is legal. ${ }^{16}$ The higher living donations in India may be associated with a history of certain exploitation which might have resulted into some nonaltruistic donors. ${ }^{17}$ After excluding these two countries, the coefficient was larger and the association was more statistically significant. The coefficient increased from 0.138 in model 4 to 0.156 in model 5 , which means that introducing a reimbursement programme increases the living donation by a factor of 1.17 or $17 \%$.

Figure 3 plots the coefficients of the covariates including year FE. The figure demonstrates that the impact of a reimbursement programme is positive and comparatively large. As to the year FE, later years have a larger impact on the donation level than the earlier years, presumably because of the overall advancement in medical systems and technologies worldwide as well as possible 'spillover effect' where the act of donation in a country or an individual positively influence other individuals/countrie over time.

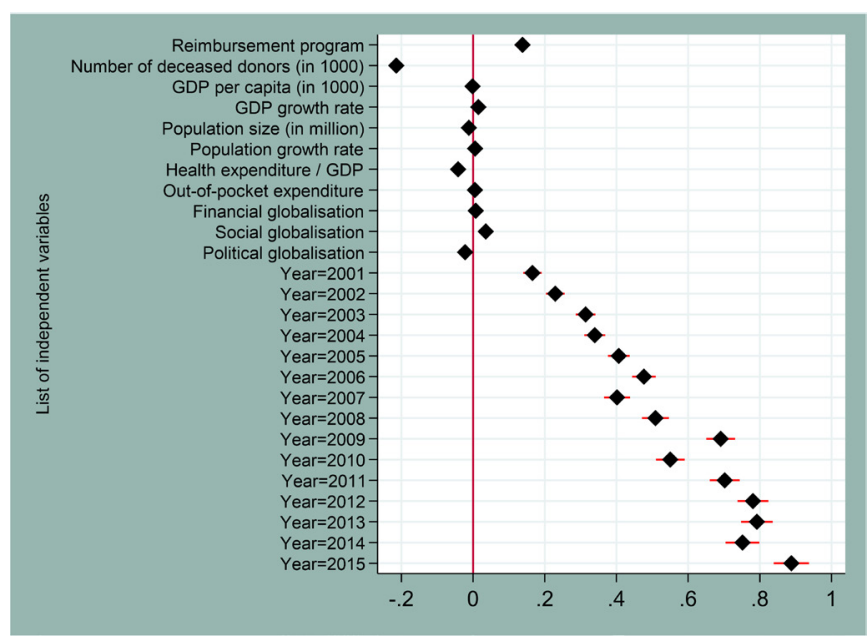

Figure 3 Coefficient plots. The coefficient plots were created using estimates of model 4 in table 2. 
Table 3 Disaggregated results by economic development

\begin{tabular}{|c|c|c|c|c|c|}
\hline & $\begin{array}{l}\text { GDP per capita } \\
<\text { US } \$ 5000\end{array}$ & $\begin{array}{l}\text { GDP per capita } \\
<\text { US } \$ 10000\end{array}$ & $\begin{array}{l}\text { GDP per capita } \\
<\text { US } \$ 30000\end{array}$ & $\begin{array}{l}\text { GDP per capita } \\
<\text { US } \$ 50000\end{array}$ & $\begin{array}{l}\text { GDP per capita } \\
>\text { US } \$ 50000\end{array}$ \\
\hline $\begin{array}{l}\text { Coefficient of reimbursement } \\
\text { programme }\end{array}$ & $0.302^{* * \star}$ & $0.490^{\star \star *}$ & $0.068^{\star \star \star}$ & $0.132^{\star \star \star}$ & -0.004 \\
\hline$P$ value & 0.009 & $<0.001$ & 0.010 & $<0.00$ & 0.966 \\
\hline Number of obs. & 295 & 523 & 836 & 1090 & 108 \\
\hline Number of countries & 38 & 60 & 80 & 99 & 11 \\
\hline
\end{tabular}

${ }^{* *} p<0.01,{ }^{* *} p<0.05,{ }^{*} p<0.1$. We estimated model 4 in table 2 where all control variables and country and year fixed effects are included.

In order to see if the above results vary depending on the level of economic development, we also ran regressions with the subsets of data divided into 2 (GDP per capita below or above US $\$ 50$ 000) and 5 (with the GDP per capita cut-offs at US $\$ 5000$, US $\$ 10000$, US $\$ 30000$ and US $\$ 50000$ ) classes. We found that reimbursement programmes contributed to a higher level of living donations in relatively less developed economies. The impact was statistically insignificant among higher income economies. These results were confirmatory in the regression with the five classes (table 3).

Finally, to examine the robustness of the results, we ran separate regressions with additional controls such as physicians per 1000 people, the poverty headcount ratio at US\$3.5 a day, economic inequality measures (Gini coefficient), measures for education achievement and human development index. These variables were not statistically significant $(\mathrm{p}>0.10)$ and did not alter the findings presented above. We also performed the analogous regressions without interpolating missing observations and confirmed that the findings hold true. Similarly, the regression excluding the countries with no documentation on reimbursement programmes did not alter the results. The regression without the country and year FE revealed that the reimbursement programme impact is larger than what we reported above. Such coefficients would inevitably be susceptible to heterogeneity bias, and thus are not presented here.

\section{DISCUSSION}

The present study suggests that implementation of a reimbursement programme has a positive impact on the country's living kidney donation level, adjusting for various conceivable covariates. The result demonstrates a stark difference from the findings of prior US-based studies that report almost no evidence that these policies were effective: Venkataramani et al. found no statistically significant effect of tax policies on the living kidney donation level in the USA where 15 states passed tax deductions and 1 state passed a tax credit policy between 2004 and 2008 to help defray potential medical, lodging and wage losses. ${ }^{9}$ Chatterjee et $a l$. also found that state-level policies designed to increase living kidney donation and transplantation during the past two decades had little to no effect. ${ }^{8}$ Wellington and Sayre drew similar conclusions based on their quantitative analyses that examined the effects of state-level tax deduction and paid leave laws. ${ }^{18}$ Lacetera et al. examined the impact of legislative efforts to alleviate the kidney and bone marrow shortages. They found that, while neither legislations had impacts on the level of kidney donation, paid-leave legislation was effective in increasing bone marrow donation. ${ }^{19}$ Direct payments to kidney donors have been prohibited by law everywhere in the world except in Iran. ${ }^{162021}$ At the same time, prior research indicates that the burden on LDs is so substantial that significant increase in the number of donors would be possible if some of these burdens were removed. ${ }^{22} 23$ The global effort to comply with the law in the presence of various burdens faced by the donors has sparked a debate over whether kidney donors should be compensated. Some experts in this area strongly oppose to the idea due to the risk of possible exploitation of the poor, excessive motivations generating a semimarket for the kidneys, adverse selection and commercialisation of the human body. ${ }^{24-26}$ Others have strong reservations, due to the fundamental concern whether an ethical compensation programme is indeed designable and implementable. ${ }^{7}$ Other experts are more amenable to the idea of direct monetary payments for kidney donation. Becker and Elias estimates that for a kidney, an amount of US\$15000 and for a liver, an amount of US\$38000 would enable markets to function. ${ }^{22} 27$ Other scholars claim that some form of non-cash, in-kind benefits could help reduce the shortage of human organs and tissue, thereby reducing the wait time for a transplant and improving quality of life among patients ${ }^{192-242829} \mathrm{At}$ the societal level, the economic benefit of a reimbursement programme is rather well established. The cost effectiveness of a reimbursement programme is achieved from treating more patients with a transplant rather than with a more costly treatment modality, that is, dialysis. ${ }^{22}$

Tong conducted interviews of 110 transplant nephrologists and surgeons from 43 transplantation programmes in 12 countries in Europe, Australasia and North America, and compiled their opinions on financial remunerations and kidney donations. The study revealed that a majority of the respondents consider that minimising disincentives support equity and justice in living kidney donation, and prioritising the removal of disincentives for LDs is acceptable. However, direct financial incentives were considered entirely unjustifiable because of the potential moral consequences and uncertain feasibility. ${ }^{30}$ These 
studies together suggest that specifying the types of ethically acceptable compensations and close examination of the effectiveness of each of such compensations are warranted. Also important is that the system in place is free of corruption or inefficiencies in implementing the policies. That being said, the present study is only the first rigorous attempt to grasp a full picture of what constitutes an effective reimbursement programme.

The reimbursement programmes included in the present study exhibited significant variations in terms of the reimbursement mechanism, eligibility criteria, duration and types of expenses reimbursed. For example, in France and Denmark, reimbursements provided by hospitals often stipulate no eligibility criteria while, in the USA, eligibility criteria vary by state or programme: some programmes focus on the reimbursement to low-income individuals, while state-level policies limit the reimbursement to state employees only. ${ }^{10}$ Similarly, while Saudi Arabia offers long-term medical insurance to donors for future medical care, Israel protects donors from the potential loss of work and/or earning after surgery. ${ }^{10}$ The positive impact reported in this study is the average effect of the presence, or lack thereof, of the programme. Analysing whether such differences in the programme implementation protocols can make some programmes more successful or not is an important question to be pursued, although it is beyond the scope of the current study.

For the deceased donations, there have been programmes that reimburse the costs related to kidney donation including funeral expenses to the family of the deceased individual. ${ }^{31}$ While the effectiveness of such programmes has not been measured, existing research suggests that such an endeavour needs to take a comprehensive approach and be accompanied by educational initiatives, public policy endeavours and clinical protocols. ${ }^{32}$ This may apply to LD programmes where education for donor candidates and clinical practice such as kidney paired exchange could be performed in conjunction with the cost reimbursement to donors.

Our results indicated that the number of deceased kidney donations has a negative impact on the number of donations. The finding may reflect the fact that LDs are more prevalent in the countries such as Korea (donor $\mathrm{pmp}=38.41$ in 2015) and Japan (donor $\mathrm{pmp}=14.76$ in 2015) where deceased donor kidneys are unavailable or unused due to cultural and/or other historical reasons. ${ }^{33}$ Clinically speaking, the unavailability of deceased donor transplants in these countries has led them to develop some advanced techniques to enable LD transplants more efficiently. For instance, clinical knowledge and expertise in performing $\mathrm{ABO}$ incompatible transplants are far more established in these countries. ${ }^{35-37}$ The western countries are yet to fully incorporate such techniques to the existing living donation programmes including kidney paired donation. ${ }^{38}$

In terms of the globalisation impact on living donations, the social globalisation and economic variables
(GDP-related variables and financial globalisation) had positive impacts on the donation level, presumably indicating that the donation level tends to go up as a nation becomes more socially and economically open, and richer. However, the main roles of these variables are as controls and the gist of the findings is that a reimbursement programme has a positive impact on the donation level even after adjusting for the country's globalisation and economic growth levels. The population size had a negative impact on the donation level presumably because some of the most populated countries had the relatively low levels of donation (donor pmp in China $=1.87$ and donor pmp in India=5.87 in 2015). The population growth was positively associated with the donation level possibly because some of the countries with the highest population growth rate (predominantly in Middle East) had a relatively high donation level. Similarly, the data revealed that Middle Eastern countries tend to have a high out of pocket health expenditures and donation levels. These countries at the same time had a relatively low ratio of private and public health expenditure to GDP, which produced a negative correlation between the variable and the donation level. Concurrently, the countries with a relatively high ratio of private and public health expenditure to GDP (Europe, Japan and USA) exhibited a relatively high donation level.

One of the advantages of applying an FE model is that the method corrects bias due to both observed and unobserved heterogeneity that are time invariant. That is, if there are country-specific traits that are time invariant, we do not need to control for those variables, and the estimators in the model are free of heterogeneity bias. However, this also means that the model is not suitable for measuring the impacts of some theoretically important variables. In many cases, these are cultural variables associated with the donation rate. For instance, a relatively high donation rate among female in India is cultural, ${ }^{39}$ and may be an important factor in explaining India's donation rate. Similarly, a high donation rate in Saudi Arabia may be attributable to the donations to unrelated recipients, which might partially reflect $\mathrm{LD}$ transplants involving immigrant donors. ${ }^{40}$ The FE model used in the current study cannot demonstrate the impacts of these factors. However, these factors were controlled in the FE estimates.

We also acknowledge that some of the known predictors were excluded from the model. For instance, religion is a known predictor for the willingness to donate. ${ }^{41}{ }^{42}$ However, composition of religious structure do not change much over time, and thus the effect of such time-invariant FE cannot be measured. In conclusion, our approach compromised these known countryspecific heterogeneities and time-invariant predictors to be taken into account for the sake of obtaining the unbiased estimate for the key predictor, that is, adoption of a reimbursement programme(s) in the 17-year long panel data. Further investigation of the effects of such traits may be warranted although such investigation will 
need to be undertaken using a different dataset with a shorter coverage of time period or in a cross-sectional study without focusing on the policy changes within countries. It is also important to note that some of the variables that are likely to be critical in determining the living donation level were not available. For instance, the number of transplant programmes or trained transplant surgeons per country per year were not available. While we made effort to accommodate the impacts of such variables using the globalisation measures, we acknowledge that the use of such composite measures neither fully accommodates the variable effects nor allows us to delineate concrete policy recommendations.

As mentioned in the Discussion section, the current study did not analyse what type of reimbursement programme is effective. In our data, the number of the countries with a reimbursement programme was relatively small compared with the number of countries without, and most of the countries with a programme appeared to have a similar set of reimbursement components. This made us impossible to disentangle the effects of different types of programmes. Further data collection and concomitant analysis are needed to discern the types of reimbursement programmes that are effective at the global level. To complement the research using aggregated data, small-scale prospective trials of various types of donor reimbursement programmes could be pursued and be comparatively evaluated to examine the feasibility and the effectiveness of individual programmes.

Most importantly, we recognise that the data compiled here answers only half the question of whether a programme of donor compensation should be implemented. The question has two parts: (1) will it work as far as increasing the number of transplants; and (2) will it be fair to all concerned, including donors. The first question is necessarily of preliminary concern. If compensation does not increase the number of transplants, then there is no need to look into question, ${ }^{2}$ so our study lays the fundamental groundwork for further analysis. We also recognise that the data compiled for the present study had comparatively high donation rates in some of the low-to-middle-income countries (LMICs) including Egypt (donor $\mathrm{pmp}=40.40$ ) and Jordan (donor $\mathrm{pmp}=31.84$ ), compared with some of the developed countries with a consistently high donation rate such as Korea (donor $\mathrm{pmp}=38.40$ ) and the Netherlands (donor $\mathrm{pmp}=30.59$; based on the 2015 figures). The global database on organ donation is compiled using individual countries' organ transplant data. Thus, it is possible that some of the LMICs erroneously count kidneys that were purchased in the black market and other unethical transplants perfomed overseas as a donation. This would inflate the size of the outcome variable for these countries, thereby distorting the coefficients as well as the significance of the covariates that are correlated with the development stage of the countries. There was a related discussion on the donation statistics on Saudi Arabia, ${ }^{40}$ and it seems that our number on Saudi Arabia does not appear to include the LD transplants that might have performed overseas. However, there are no references that we can use to check the accuracy of the statistics for the statistics in other countries.

\section{CONCLUSION}

In this evaluation study of country-level LD reimbursement programmes implemented globally between 2000 and 2016, the impact of such a programme on overall donation numbers was substantial. We predict that living kidney donation would increase by a factor of 1.16 as a result of a reimbursement programme. The result indicates that a reimbursement programme has a potential to bring substantial economic and welfare benefits through improved access to kidney transplantation. This is a fundamental first step in determining the future direction of research endeavour, which should include not only the type of reimbursement programmes that is effective in increasing donation rates but also the content of the programmes that is fair and just in other respects.

Contributors Authors are equal contributors.

Funding This study was funded by National Science Foundation, USA (EAGER: ISN:/1838306).

Map disclaimer The depiction of boundaries on this map does not imply the expression of any opinion whatsoever on the part of BMJ (or any member of its group) concerning the legal status of any country, territory, jurisdiction or area or of its authorities. This map is provided without any warranty of any kind, either express or implied.

\section{Competing interests None declared.}

Patient consent for publication Not required.

Provenance and peer review Not commissioned; externally peer reviewed.

Data availability statement Data are available upon request.

Open access This is an open access article distributed in accordance with the Creative Commons Attribution Non Commercial (CC BY-NC 4.0) license, which permits others to distribute, remix, adapt, build upon this work non-commercially, and license their derivative works on different terms, provided the original work is properly cited, appropriate credit is given, any changes made indicated, and the use is non-commercial. See: http://creativecommons.org/licenses/by-nc/4.0/.

\section{ORCID iDs}

Abu Bakkar Siddique http://orcid.org/0000-0002-9964-7511

Naoru Koizumi http://orcid.org/0000-0001-8722-0898

\section{REFERENCES}

1 Abecassis M, Bartlett ST, Collins AJ, et al. Kidney transplantation as primary therapy for end-stage renal disease: a National Kidney Foundation/Kidney Disease Outcomes Quality Initiative (NKF/ KDOQI ${ }^{\mathrm{TM}}$ ) conference. Clin J Am Soc Nephrol 2008;3:471-80.

2 Abouna GM. Organ shortage crisis: problems and possible solutions. Transplant Proc 2008;40:34-8.

3 US Dept. of Health and Human Services. [USC02] 42 USC 274: Organ procurement and transplantation network [Internet], 2020. Available: https://uscode.house.gov/view.xhtml?hl=false\&edition= prelim\&req=granuleid\%3AUSC-2014-title42-section274\&num=0

4 McCormick F, Held PJ, Chertow GM. The terrible toll of the kidney shortage. J Am Soc Nephrol 2018;29:2775-6.

5 Muzaale AD, Dagher NN, Montgomery RA, et al. Estimates of early death, acute liver failure, and long-term mortality among live liver donors. Gastroenterology 2012;142:273-80.

6 Segev DL, Muzaale AD, Caffo BS, et al. Perioperative mortality and long-term survival following live kidney donation. JAMA 2010;303:959. 
7 Fry-Revere S. Solving the organ shortage by giving living organ donors what they deserve. J Hosp Ethics 2018;5.

8 Chatterjee P, Venkataramani AS, Vijayan A, et al. The effect of state policies on organ donation and transplantation in the United States. JAMA Intern Med 2015;175:1323.

9 Venkataramani AS, Martin EG, Vijayan A, et al. The impact of Tax policies on living organ donations in the United States: Tax policies and organ donations. Am J Transplant 2012;12:2133-40.

10 Sickand M, Cuerden MS, Klarenbach SW, et al. Reimbursing live organ donors for incurred non-medical expenses: a global perspective on policies and programs. Am J Transplant 2009;9:2825-36.

11 Gygli S, Haelg F, Potrafke N, et al. The KOF globalisation indexrevisited. Rev Int Organ 2019;14:543-74.

12 Dreher A, Gaston N. Has globalization increased inequality? Rev Int Econ 2008;16:516-36.

13 Vogli RD, Kouvonen A, Elovainio M, et al. Economic globalization, inequality and body mass index: a cross-national analysis of 127 countries. Crit Public Health 2014;24:7-21.

14 Baltagi B. Econometric analysis of panel data. John Wiley \& Sons, 2008.

15 Guimarães P. The fixed effects negative binomial model revisited. Econ Lett 2008;99:63-6.

16 Ghods AJ, Savaj S. Iranian model of paid and regulated livingunrelated kidney donation. Clin J Am Soc Nephrol 2006;1:1136-45.

17 Jha V. Paid transplants in India: the grim reality. Nephrol Dial Transplant 2004;19:541-3.

18 Wellington AJ, Sayre EA. An evaluation of financial incentive policies for organ donations in the United States. Contemp Econ Policy 2011;29:1-13.

19 Lacetera N, Macis M, Stith SS. Removing financial barriers to organ and bone marrow donation: the effect of leave and Tax legislation in the U.S. J Health Econ 2014;33:43-56.

20 Fry-Revere S. The kidney sellers: a journey of discovery in Iran. Durham, NC: Carolina Academic Press, 2014.

21 Nayebpour MM, Koizumi N. The social stigma of Selling kidneys in Iran as a barrier to entry: a social determinant of health. World Med Health Policy 2018;10:55-64.

22 McCormick F, Held PJ, Chertow GM, et al. Removing disincentives to kidney donation: a quantitative analysis. J Am Soc Nephrol 2019;30:1349-57.

23 Gaston RS, Danovitch GM, Epstein RA, et al. Limiting financial disincentives in live organ donation: a rational solution to the kidney shortage. Am J Transplant 2006;6:2548-55.

24 Frey BS. Motivation as a limit to pricing. J Econ Psychol 1993;14:635-64.

25 Richard T. The gift relationship (Reissue): from human blood to social policy. Policy Press, 2018: 356.
26 Roth AE. Repugnance as a constraint on markets. J Econ Perspect 2007;21:37-58.

27 Becker GS, Elías JJ. Introducing incentives in the market for live and cadaveric organ donations. J Econ Perspect 2007;21:3-24.

28 Leider S, Roth AE. Kidneys for sale: who disapproves, and why? Am $J$ Transplant 2010;10:1221-7.

29 Rodrigue JR, Crist K, Roberts JP, et al. Stimulus for organ donation: a survey of the American Society of transplant surgeons membership. Am J Transplant 2009;9:2172-6.

30 Tong A, Chapman JR, Wong G, et al. Perspectives of transplant physicians and surgeons on reimbursement, compensation, and incentives for living kidney donors. Am J Kidney Dis 2014;64:622-32.

31 Rodríguez-Arias D, Wright L, Paredes D. Success factors and ethical challenges of the Spanish model of organ donation. Lancet 2010;376:1109-12.

32 Schold JD, Segev DL. Increasing the pool of deceased donor organs for kidney transplantation. Nat Rev Nephrol 2012;8:325-31.

33 Bresnahan M, Lee SY, Smith SW, et al. A theory of planned behavior study of college students' intention to register as organ donors in Japan, Korea, and the United States. Health Commun 2007;21:201-11.

34 Chen C-L, Kabiling CS, Concejero AM. Why does living donor liver transplantation flourish in Asia? Nat Rev Gastroenterol Hepatol 2013;10:746-51.

35 Takahashi K, Saito K. Present status of ABO-incompatible kidney transplantation in Japan. Xenotransplantation 2006;13:118-22.

36 Takahashi K, Saito K, Takahara S, et al. Excellent long-term outcome of ABO-incompatible living donor kidney transplantation in Japan. Am J Transplant 2004;4:1089-96.

37 Hwang J-K, Kim Y-K, Kim J-M, et al. Comparative analysis of ABO-incompatible living donor kidney transplantation with $\mathrm{ABO}$ compatible grafts: a single-center experience in Korea. Transplant Proc 2013;45:2931-6.

38 Karami F, Gentili M, Nayebpour M, et al. Optimal integration of desensitization protocols into kidney paired donation (KPD) programs. Oper Res Health Care 2019;22:100198.

39 Bal MM, Saikia B. Gender bias in renal transplantation: are women alone donating kidneys in India? Transplant Proc 2007;39:2961-3.

40 Horvat LD, Shariff SZ, Garg AX, et al. Global trends in the rates of living kidney donation. Kidney Int 2009;75:1088-98.

41 Oliver M, Woywodt A, Ahmed A, et al. Organ donation, transplantation and religion. . Oxford University Press, 2011: 26. 437-44.

42 Ismail SY, Massey EK, Luchtenburg AE, et al. Religious attitudes towards living kidney donation among Dutch renal patients. Med Health Care Philos 2012;15:221-7. 